City University of New York (CUNY)

CUNY Academic Works

Publications and Research

York College

2020

\title{
AN ANALYSIS OF ASTROPHOTOGRAPHY: HOW ACCURATE IS THE PHOTOGRAPHY OF SPACE?
}

Denice Morales

Long Island City High School

Rajendra Persaud

NASA MUREP Aerospace Academy

Nazrul I. Khandaker

cUNY York College

Omadevi Sing

cUNY York College

Matthew Khargie

CoEnterprise

\section{How does access to this work benefit you? Let us know!}

More information about this work at: https://academicworks.cuny.edu/yc_pubs/285

Discover additional works at: https://academicworks.cuny.edu

This work is made publicly available by the City University of New York (CUNY).

Contact: AcademicWorks@cuny.edu 


\section{AN ANALYSIS OF ASTROPHOTOGRAPHY: HOW ACCURATE IS THE PHOTOGRAPHY OF SPACE?}

MORALES, Denice, LONG ISLAND CITY HIGH SCHOOL, 14-30 Broadway, Long Island City, NY 11106, PERSAUD, Rajendra, NASA MUREP

AEROSPACE ACADEMY, 8740 97th Street, Woodhaven, NY 11421, KHANDAKER, Nazrul I., Geology Discipline, Earth and Physical Sciences, York College Of CUNY, 94-20 Guy R. Brewer Blvd, Jamaica, NY 11451, SINGH, Omadevi, NASA MUREP AEROSPACE ACADEMY, York College - City University of New York, 94-20 Guy R. Brewer Blvd., Jamaica, NY 11451 and KHARGIE, Matthew, CoEnterprise, 45 West, 36 TH Street, New York City, NY 10018

\section{Introduction}

Astronomy is a gateway into science; the thoughts and questions it acknowledges create a trip of shock and awe. Astrophotography is imagery of astronomical object (the nighttime sky. The first graphic of an astronomica object was taken in 1840, however it wasn't until the late nineteenth century that advances in technological know-how allowed for designated stellar photography. It: greatest appeal are the riveting photos produced with the advent of location telescopes, adaptive optics, robotized missions, and the communications era, which accordance to (Rosenberg et al. 2014) "inspire us and promise options to massive questions". The photographs "provide a gateway to lengthen scientific understandin with the aid of clarifying how nature behaves and how the scientific strategy leads u to decorate fashions of this habits and then difficultythese fashions to rigorous tests (National Research Council Astronomy and Astrophysics Survey Committee 2000).

\section{Methods:}

To gather knowledge and learn more about previous studies, is to go on space careers, stem education journal.

Which classes help students understand: Theoretical classes teach participants how to mount, balance, and align thetripods. telescopes, and cameras. An exercise session halfway through the session should occu in the place the college students had their first contact with the equipment, followed by photograph acquisition session a few days afterwards. It will make them understand how to take the most accurate pictures.

Citation

"Astrophotography Tips \& Techniques." Sky \& Telescope, skyandtelescope.org/astronomy. resources/astrophotography-tips

\section{How it helps students:}

The astrophotography route used to be designed for undergraduate college students pursuing studies in social sciences, business, or arts. The route focused on giving college students a regularly occurring overview of modern-day astronomy, fostering the use of a scientific lexicon, and reviewing information discount and picture processing methods. The dream has been to create college students educated in the herbal sciences and train practicable novice astronomers and citizen scientis
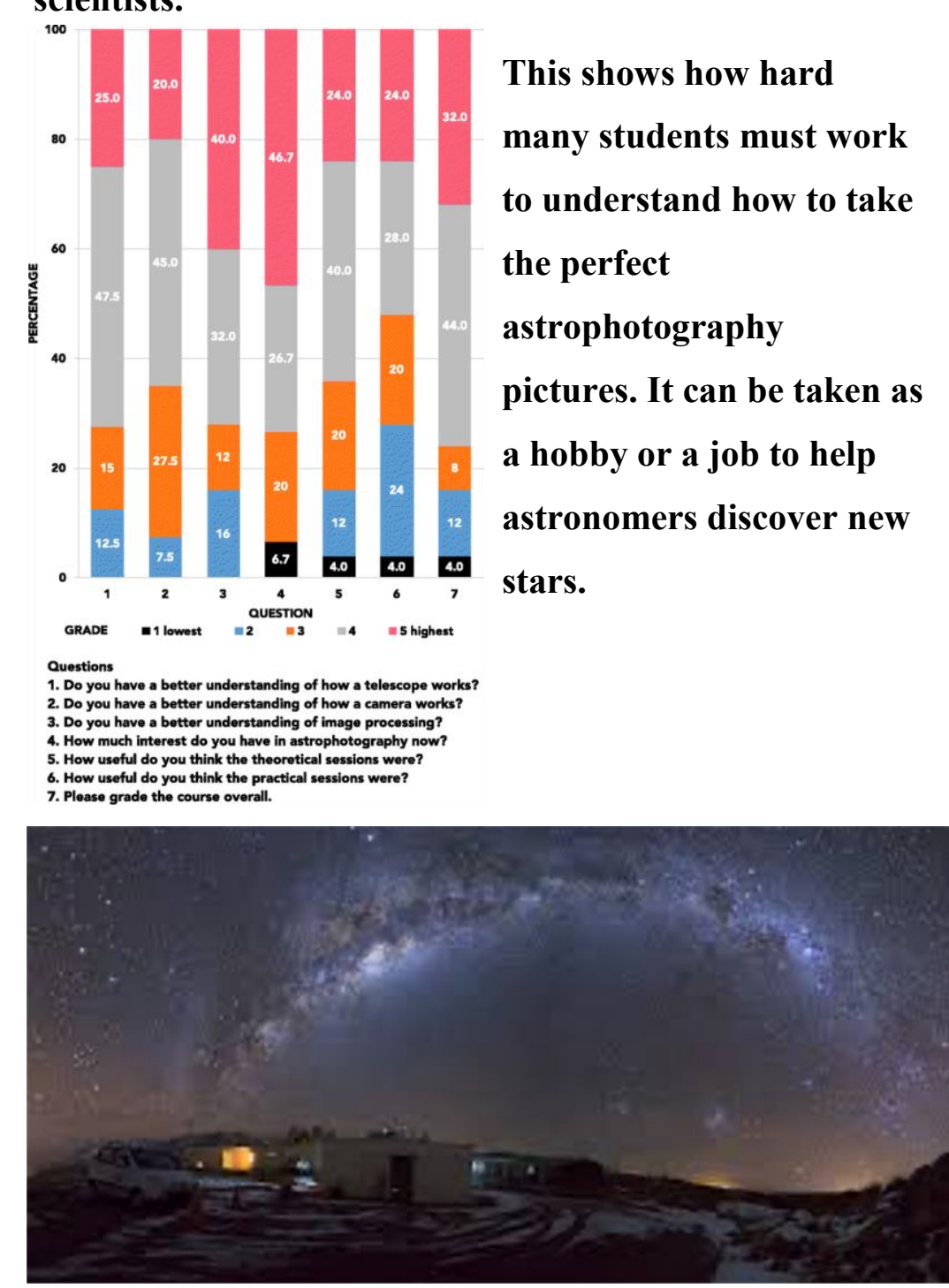

\section{Abstract:}

The current research goal is to talk about astrophotography that is designed to interact with non-STEM majors in the natural sciences, and to teach future or beginner astronomers and citizen scientists. The course depends on constructivist tutorial strategies to instruct records, cut prices in photo processing strategies, and at the same time address mathematical anxiety. The goal is to create an awesome ride in the natural sciences, which has been traditionally linked to imparting pertinent education to a cohort of citizen scientists and novice astronomers - businesses which historically have analyzed an amazing volume of files (both recent and historical archives) and have accomplished countless discoveries. Those enrolled in the route demonstrated a greater grasp of records reduction, photography processing, and telescope and digicam use. Most college students had been keen to take up astrophotography as a hobby. Thus, opening the course may lead to creating future citizen scientists and novice astronomers. We found that the strategy required to exercise astrophotography is to create an herbal constructivist involved in instructing our environment. The route can be reproduced somewhere else to train non-science college students with methods in records discount and photo processing, deemed an effective experience to enable them to access STEM fields and appreciate the interconnectedness with astrophotography. It can be considered as a recruiting tool in STEM disciplines.

\section{Percentage:}

A majority of college students (69\%) graded the usefulness of theoretical classes equal or above four (out of five), in contrast to $62 \%$ for the photo acquisition sessions; the distinction is in all likelihood due to the complexity of the photo acquisition session, the place they are anticipated to make knowledgeable selection primarily based on preceding knowledge. Students overwhelmingly $(89 \%)$ regarded the route as a very good/excellent $(24)$ workout in science. An extended hobby in astronomy was once additionally pronounced via $71 \%$ of the students. The solutions are proven in Fig. 2

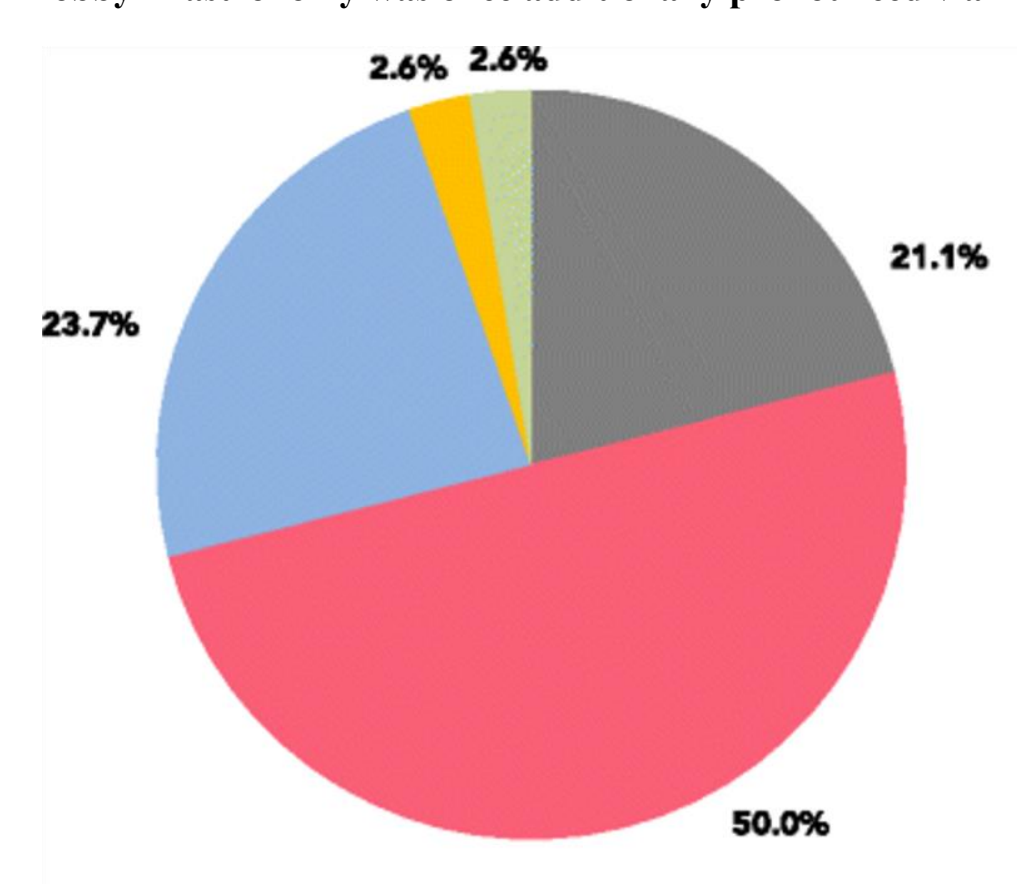

Course enrollment. Breakdown of the educational predominant enrollment of pupil populace in the first social sciences) and CNAS (college of herbal and agricultural sciences)

The theoretical lessons included the following subjects: archives of (astro)photography, the use of astrophotography, moderate pollution, the importance and nature of the celestial objects which are going to be photographed, publicity time, shutter speed, digicam detector sensitivity (International Organization for Standardization, ISO), object tracking, movie star trails, focus, aperture, signal-tonoise ratio, digicam sensors, kinds of telescope and mounts, focal length, magnification, celestial coordinates, and the value and correction produced by the use of dark/flat/bias images. Additionally, university college students had been given a list of steps for exceptional practices in astrophotography. These commonplace facts ensured they knew how to first: technique the handy equipment, second: allowed them to make educated options on publicity situations and sensitivity at the same time as the use of the camera, and third: geared them up to take as many snapshots as

- Business = $=$ CHASS | CNAS - Engineering Undecided $\begin{aligned} & \text { possible to enlarge the signal-to-noise ratio in st } \\ & \text { the procurement of bias, dark, and flat images. }\end{aligned}$ 